\title{
Conflict and Crisis Management: A Theoretical Comparison
}

\author{
Wobodo, Chinonye Chris ${ }^{1 *} \quad$ Orianzi, Richard ${ }^{*} \quad$ Oko-Jaja, Bethel ${ }^{3}$ \\ Doctoral Candidates, Department of Management, Faculty of Management Sciences, \\ Rivers State University, Port Harcourt
}

\begin{abstract}
This study conceptually took a comparative overview of conflict and crisis phenomena as it relates to the current state of business operating environment which is riddled with so many threats and uncertainties. In doing this, extant reviews were made on the two variables in order to demystify the controversies surrounding their manifestations and impacts on the organization. Consequently, we discovered that both conflict and crisis phenomena are indispensable part of human existence and environmental character. The comparative analysis explored revealed that both phenomena impact on the organization negatively but at varied degrees. Crises are mainly associated with disaster and hazard that ruthlessly negates the functionality of the organization where urgent response is not taken to mitigate it. While this goes, conflict is not completely a dangerous phenomenon in its entirety as people superficially perceive it to be. It is like a coin with two sides, the head and the tail; where the head represents success and the tail represents failure. The functional (head) aspect impacts on the organization positively while the dysfunctional (tail) aspect leaves the organization with negative and destructive consequences just like crisis. Therefore, we conclude that both conflict and crisis are inherent phenomena among people and their environments which cannot be eradicated but managed through the adoption of context-fit strategies. In this regards, we recommend that: i) in the face of conflict and crisis, the choice of management approach should mainly be guided by its type, level and phase ii) since conflict and crisis are endemic factors, managers should regularly carry out both internal and external diagnosis as a means of identifying early warning signs of disruptive conflicts and natural crisis's incubation periods and possible manifestation time so as to provide adequate proactive and reactive response strategies timely.
\end{abstract}

Keywords: Conflict, crisis, management, compromise, forcing, collaboration, proactive-ness, reactiveness, comparative analysis

DOI: $10.7176 / \mathrm{EJBM} / 12-2-03$

Publication date: January $31^{\text {st }} 2020$

\section{Introduction}

Studies show that every organization is goal-seeking in nature and the extent to which such goal is achieved is mainly dependent on how immersed the organization is to its operating environment. For instance, Gabriel (2018) opines that organizations are open system that interface constantly with external forces such as government agencies, customers, and suppliers. It is therefore on the basis of this interaction that an unbreakable interdependency is established between business and the society. This mutuality reflects in the manner the environment provides the organization with all of its necessary input resources which according to Bouquet and Birkinshaw (2008) include money, human capital and technology. On the other hand, the society (environment) depends on the organization for quality goods and services such as the car we drive, the cloth we wear, the food we eat, the banking and medical services we receive from the organization for our satisfaction. It is on this premise that organizations initiate exchange relationships with other actors to obtain the resources on which they are dependent (Cropanzano \& Mitchell, 2005).

However, despite this interdependency, the organization and the society are also observed as having incompatible goals. This is as the goal of the business is centered on making maximum profit at the most efficient and effective manner, while the society on the other hand is concerned with getting the best of service and product at a relatively cheap price or cost. Even among organizations there is also high level of incompatibility of interest as every organization wants to be the market leader in their various organizational fields, thereby creating an unquenchable rivalry among them. Given this observable rivalry among businesses as well as the goal incompatibility between business and society; sometimes these degenerates to conflict and crisis situation which if left unattended to may lead to corporate frustration and in most cases outright closure of the business. While one aspect of conflict such as functional conflict may be encouraged for the good of the organization, crisis and dysfunctional aspect of conflict on the other hand is considered a survival threatening phenomenon which can occur as a result of natural forces, managerial negligence and incompatible interest. Iheriohanma (2007) further buttressed this claim when he assert that management practice of exclusionism, neglect of power sharing mechanism which ensures partnership amongst stakeholders in the workplace and derogation of organizational communication pattern contribute in breeding disharmony and conflict in contemporary workplaces. And where this persists, it leads to human-induced crisis, especially when people feel that there is need to defend and restore their right in the face of injustice. 
This observation reinforces Bello (2011) position that Nigerian business operating atmosphere is generally characterized by array of perturbations and uncertainties provoked by macro environmental forces such as unstable business regulatory framework, inadequate power supply, political instability and technology inadequacies. Similarly, Wobodo, Asawo and Asawo (2018) corroborates this view when they stated that due to the complex, dynamic and competitive nature of the environment, organizations are faced with immeasurable challenges emanating internally and externally. They further identified these challenges as including political imbalance, technological shifts, terrorists' attacks, natural disaster, market rigging by the government, employees' educational and cultural differences, wrong structural configurations etc. In congruence with these divergent influences conflict and crisis wades in the performance and survival of an organization, the scholars feel that there is need to draw up an in-depth comparative overview of the concepts in order to provide additional insights on the subject matter.

Although, scholars have undertaken several empirical and theoretical studies on these subject matter in different contexts; for instance, in the area of crisis management, Oparanma and Wechie (2014) investigated crisis management processes to ensure effective and continuous performance. Karam (2018) assessed crisis management with focus on strategic planning in 5-Star Hotels while Wobodo and Oparanma (2019) examined crisis management and corporate resilience of multinational companies in Port Harcourt. In the case of conflict management, Taher, Das and Rashed (2008) carried out a study on conflict management and its impact on organizational performance in some industrial enterprises in Bangladesh. Kassim and Ibrahim (2014) investigated conflict management styles and organizational commitment among banks' employees in Penang. Akume and Abdullahi (2013) focused on the challenges and prospects of effective industrial conflict resolution in Nigeria. Similarly, Wobodo (2019) examined conflict management strategies and industrial harmony in Rivers State University, Port Harcourt. Amid all of these studies, it is shocking that no study focusing on comparative assessment of conflict management and crisis management was observed, especially within the context of Nigeria's work environment. Hence, this study intends to fill this lacuna through a conceptual review.

\section{The Meaning and Nature of Conflict and Crisis Management}

The concept of conflict and crisis has been identified in management literature by several scholars and managers in practice as one of the endemic phenomena which every organization is bound to experience and respond to at any stage of its life circle as a result of its constant interaction and interdependence with the environment. However, the processes of formation of conflict and crisis differ significantly. While conflict may arise from personality differences and goal incompatibility, crisis occur as a result of both natural and human action. In the same vein, Sapriel (2003) alludes that crisis occur mainly as a result of managerial errors arising from leadership and decision making approaches of decision makers. Based on the forgoing discussion, the following paragraph discusses the dynamics of the concepts individually for clarity purposes.

\subsection{The Concept of Conflict Management}

According to Robbins (2005) conflict is a situation that surfaces the moment one party perceives that another party has adversely affected, or is about to gravely affect something that the first party desires. Similarly, Mullins and Christy (2013) assert that conflict is a behavior projected to obstruct the achievement of some other person's plans. These definitions corroborate with Sims (2002) position that conflicts within organizations usually emanate as a result of incompatible goals or disagreements among individuals and groups. In the organization, conflict can manifest in the form of functional and dysfunctional conflict. When functional conflict occurs within a group or team, it is considered to be creativity, innovation, and team building driven; which means that the emergence of functional conflict within teams and groups bring about healthy and constructive criticisms, suggestions and competition needed to improve one another's skills which in the long run leads to better group productivity and performance (Wobodo, 2019). It is usually achieved through diversity of opinions that help teams to identify new ways of solving problems and handling issues (Lepsinger, 2018). Furthermore, Robbins, Judge and Vohra (2011) iterate that functional conflict is constructive in nature and supports organizational objectives and enhances performance outcome.

On the other hand, dysfunctional conflict is destructive in nature and has the tendency to obstruct organizational goal attainment (Wobodo, 2019). Consequently, in modern organization managers strive to ensure that dysfunctional conflict is discouraged. This is because the actors in this kind of conflict engage in different forms of counter-productive work behavior like sabotage, self-preservation behaviors such as withholding of information, refusing to help others, showing lack of interest to shared goal etc. (Lepsinger, 2018). The implication of this is that if it is allowed to continue without managing it timely and adequately, it has the capacity to break an organization down. Just as Maltz and Kohli (2000) observed that interdepartmental conflicts can distort resourcefulness in other department; which of course is not a healthy phenomenon for group cohesiveness within the organization. Again, dysfunctional conflict can result in information hoarding and formation of coalitions to block other group's proposals and interests thereby creating room for industrial disharmony among members.

Furthermore, Deutch and Coleman (2006) revealed that some of the potential causes or sources of conflict 
include differences in knowledge, beliefs and basic values; competition for position, power and recognition; a drive for autonomy; personal dislike; and differing perception or attributes brought about by the organizational structure, different role structure, heterogeneity of the workforce, environmental changes, differences in goals, feeling of insecurity, diverse economic interest, loyalties of groups, and value discrepancies; which were all considered at various stages as major causes of conflict in organization. In this regard, effective conflict management must be given utmost attention. Accordingly, Wobodo (2019) maintains that effective conflict management is a veritable approach to solving organizational problems, be it intra-organizational or interorganizational conflict.

Therefore, conflict management is viewed as the process through which interpersonal communication is utilized to allow two conflicted parties to reach an amicable and satisfactory point of agreement (Omoluabi, 2001). In the same vein, (Wobodo, 2019) stated that it is the adoption of appropriate mechanisms to undermine the dysfunctional implications of conflict while enhancing its functional aspect in order to improve learning and effectiveness of the organization. Leaning on these views, it means that through a well-defined conflict management tool, people in conflict can quickly resolve their differences without putting the organization's goal in jeopardy. It is also essential to note that effective conflict management is considered necessary today because of the alarming diversity characterizing modern organization's settings. This manifests in areas such as religion, gender, profession, age, generational class, personality, values etc. of the workforce.

\subsubsection{Conflict Management Techniques}

Studies indicate that there are different methods or techniques managers or employees can adopt to resolve conflict in the organization. However, the adoption of a given strategy is mainly influenced by the complexity of the problem as well as the capacity variation of the people in conflict. Also, Thakore (2013) stated that there are two basic issues people consider before opting for a particular conflict resolution technique, the first one is achieving one's personal goals which is usually driven by the fact that every individual have a goal that conflicts with another person's goal which may be of high importance to him, or it may be of little importance to him. Secondly, the desire to keeping a good relationship with the other person may also influence the approach one may want to adopt in handling conflict situation. Based on these views, the following techniques are adopted in this study as used by other scholars in the past.

\subsubsection{Compromising Technique}

This technique is characterized with negotiation and a high degree of flexibility. According to Burnside (2008) the adoption of compromising approach creates an atmosphere of win - lose outcome among the parties in conflict. It refers to the appeasement that takes place where one party in dispute is willing to let the other party have their way. This is so because it is expected that for parties in conflict to arrive at an agreeable resolution, each party must give up something such that there is no clear winner or loser. Most times people do this because they value relationships over the issue in context or because one party cannot contend with the other party.

\subsubsection{Forcing Technique}

This approach to conflict resolution is characterized with a win-lose outcome. Accordingly, Thakore (2013) iterates that this technique is associated with a situation in which one party in conflict attempts to gain complete control of everything under contention without minding the interest of the other party. In view of this definition, we may say that such situation can only prevail where the second party does not have what may be required to effectively prosecute the context with their opponents thereby making them vulnerable to imminent failure. However, a situation where this type of absolute dominance prevails, the implication is that it will create an atmosphere of industrial disharmony through continuous sabotage of one another's efforts thereby putting the fate of the organization on the cross fire. Again, with the manifestation of these outcomes, we may argue that the adoption of forcing style to managing conflict should be discouraged in the organization because of its autocratic undertones; which instead of resolving the conflict only ends up creating more room for further dysfunctional situation

\subsubsection{Collaboration Technique}

According to Salami (2009) the adoption of collaboration strategy in the management of conflict situation ranks high on both assertiveness and cooperativeness. On the other hand, Calha (2017) sees collaboration strategy as an affirmative and obliging means of conflict management which usually results in a win-win settlement. Similarly, McShane and Von Glinow (2000) added that collaboration carries the highest level of win/win orientation that brings about information sharing, openness, and clarification of issues at the point of conflict to come up with solution acceptable to both parties. Snell (2002) maintains that collaboration serves to maintain and strengthen work relationships for both parties. This is as it allows people in conflict to subsume their original interest and then work in synergy to achieve a common goal. Consequently, Hotepo, Asokere, Abdul-Azeez and Asokere (2010) contend that effective use of collaborative strategy may result in positive work behavior and attitudes hence; it promotes cooperation and integrity in the workplace that reduces conflicts 


\subsection{The Concept of Crisis Management}

According to Karam (2018) crisis refers to as a low probability-high impact phenomenon that threatens the viability of the organization. It is seen as an inescapable disruption every organization is bound to encounter at any point in their life time and this most times occurs with or without sufficient warning signals. No wonder, Oparanma and Wechie (2014) argue that no organization can operate without the occurrence of unexpected or unplanned business interruptions like strikes, layoffs, allegation of misconduct, products recalls, equipment explosions, and government policies. This is basically because no social system operates successfully without being in constant interaction with its operating environment (Koontz \& Weihrich, 1999; Wobodo, Asawo \& Asawo, 2018; Wobodo, 2019). Therefore, whatever happens in the environment good or bad always impact on the organization in such a manner that their survival is put to test if urgent response is not taken to mitigate it. Crisis can be triggered by human actions such as wrong managerial decision and practices as well as natural causes such as earthquake, storm, ocean surge etc. which organization must swiftly react to if they must survive.

The manner in which organizations respond to each crisis situation is dependent on how crisis management ready they are before, during and after the crisis occurrence. This assertion reinforces the position of Wobodo and Oparanma (2019) when they contend that the ability of organization to survive in the face of perturbations and bounce back successfully is tied to the efficacy of their crisis management approach. In view of this, crisis management has been defined as actions that cover the immediate response to a disaster, recovery efforts, mitigation, and preparedness efforts to reduce the impact of possible future crises (Mehrotra, Znati \& Thompson, 2008). Furthermore, Ronez (2014) describes it as the process of anticipating, identifying, preventing and managing potential disasters by setting up appropriate plans to deal with crises when they manifest. In view of the destructive effect of crisis when it is not properly managed, Wobodo and Oparanma (2019) argued that to achieve a successful crisis management, organizational leaders must have an understanding of the root cause of the crisis situation so as to enable them adopt strategies that suit the crisis hence, some crises can be prevented while others can only be managed.

Accordingly, Sullivan (2003) spotted out five forms of crises that are likely to befall organizations at any level of their life circle as including financial, public relation, strategic, natural or sudden and smoldering crisis.

\subsubsection{Financial Crisis}

This crisis situation occurs as a result of an organization's financial status, especially in the banking sector when a bank is unable to pay out cash to its customers due to liquidity failure thereby causing a run on the bank; and consequently drag the image of the organization to the mud if a swift action is not taken to contain it.

\subsubsection{Public Relations Crisis}

This type of crisis arises when organizations out of their carelessness or deliberate unethical conduct are being prosecuted by individual victims of their actions/inactions through the media or a competent court of law which may poses a threat to the good public image of the organization. The implication here is that if nothing is quickly done to remedy the situation, the organization may end up losing customers patronage to their closest rivals because of negative public perception about the company's practices (Wobodo \& Oparanma, 2019), by the society.

\subsubsection{Strategic Crisis}

These are crises induced by certain aspect of changes in the business environment that requires constant adaptation in order not to be left behind (Wobodo \& Oparanma, 2019). For instance, in the technological environment, every minute of the day scientists are rolling out sophisticated machines and gadgets for improved business operations, and any organization desiring to remain viable and competitively ahead must be able and ready to synchronize these rapid changes. Practically, before the emergence of the computer age, organizations were virtually relying on typewriter to carry out their clerical tasks but when they discovered the ease associated with the use of the computer over the typewriter, there was a massive loyalty swap which immediately threw the typewriter manufacturing company into early entropy while the computer manufacturers are still in business till today growing fat

\subsubsection{Natural Crisis}

These are crises caused by nature; they are often seen as the act of God (Wobodo \& Oparanma, 2019). This is because it happens naturally without any human inducement. It can manifest in the form of flood, earthquake, hurricane, volcanic eruption, tsunamis, windstorm etc. The implication of either of these events on the organization is often dependent on their severity but some literature explicitly declared that they are usually destructive. As such, organizations are required to always be crisis prepared in order to swiftly ameliorate their damaging effect.

\subsubsection{Smoldering Crisis}

The Institute of Crisis Management (2003) sees smoldering crisis as any major business problem which is not generally known within or without the organization which generates negative news coverage or when it goes public and could result in more than a predetermined amount in fines, penalties, legal damage award, and unbudgeted expenses. As observed in Oparanma and Wechie (2014), they associated this crisis with man-made problems which are characterized as disruptions that can cause injuries to lives and properties through some acts of criminal negligence such as intentional acts of omission which can arise from several motives. They further exemplified 
this in terms of unlawful disclosure to employees, investors, customers, vendors and or government official, accidentals and explosions arising from inadequate tool maintenance, indication of significant legal and judicial or regulatory action against the business.

\subsection{Approaches to Managing Crisis at the Workplace}

There are a number of styles or strategies organizational leaders could adopt in dealing with crisis situations such as escape strategy, cooperation strategy, confrontation strategy, and containment strategy (El-Mahdi, 2002; AbdElaal, 2008). Yet others adopt a proactive strategy and reactive strategy (Hough \& Spillan, 2005). To us in this study, we adopted Hough and Spillan (2005) typology due to its perceived suitability in this current study.

\subsubsection{Proactive Strategy}

Proactive organizations are considered as die-hard organization. They rather than simply reacting to a crisis situation actively influence and engage it. Robbins et al., (2011) described proactiveness as a personality attribute that describes people who are prone to take actions to impact on their environment; so also does organization. Proactive people and organization respond and face adversity and change head-on (Wobodo, Asawo \& Asawo, 2018). Rotter (1966) concluded that proactive organization tends to have an internal locus of control where they believe that they have the capacity and the responsibility to control their own fate. It measures the extent to which an organization is self-motivated and in such a manner that they not only succeed in the midst of obstacles and challenges but also maintain balance and stability while preparing ahead of subsequent changes. Given this assertion, proactive organization focuses on stabilizing their strength over a change through positive behaviors and actions. Frankl (2013) believes that proactive tendency enables organization to successfully preserve their strength and confidence in the midst of obstacle, no matter how traumatic.

\subsubsection{Reactive Strategy}

According to Bailey (2016) being reactive is associated with having the ability to confront pressure that comes your way in real time. In relation to crisis management, it is a situation in which planning decisions take place during and after the crisis situation (Karam, 2018). A reactive crisis manager is one who will usually wait for crisis to occur or emerge before taking necessary steps to manage and eradicate it in order to achieve continuity in business operations (Wobodo \& Oparanma, 2019). This strategy is characterized by quick thought processes which are logical and planned to turn things around (Bailey, 2016). Reactive thinkers find it easy to make snappy decisions as this strategy does not lend itself to analyzing what might be required sometime in the future.

\section{Comparison of Conflict and Crisis}

Within the business settings, conflict and crisis are two inseparable phenomena every organization will have to continuously deal with because of their regular interaction with the environment in which they operate. Both conflict and crisis are endemic to the organization and by their nature has the capacity to force an organization into early entropy if appropriate mitigation mechanisms are not put place. However, irrespective of their endemic nature, they vary in their manifestation patterns and the degree of influence they wade in the organization.

First, in terms of manifestation, conflicts occur mainly as a result of clash of interest between people (stakeholders) in the organization, especially in their quest for scarce resource. Such clash may also arise from interpersonal battles and disagreements arising from mismatch of behavior and attitudes (Maharaj-Sharma, 2008). On the other hand, crises are triggered by both human actions and natural forces. Natural forces unleash havoc on the organization with or without warning signs thereby making its containment a serious task requiring much planning and commitment. Just as Mehrotra, Znati and Thompson (2008) argued that coping with crisis situations triggered by nature or man's action is a critical challenge for modern society. Conversely, the human aspect of crisis occurs as a result of long time unresolved conflicts and managerial blunders. For instance, Sapriel (2003) argued that such crises are traceable to management inactions or neglect. The scholar further stressed that $65 \%$ of crises occur suddenly while $35 \%$ builds up. In Nigeria, a typical instance of a case of managerial blunder or negligence that resulted in deep crisis is the infamous Ogoni and Shell crisis of 1993 that led to the destruction of properties and the death of many local people, following the protest led the by host community activists who accused the oil and gas company of neglecting community's interests and expectations as well as the environmental damages caused as a result.

Secondly, in terms of impact, conflict and crisis wades disproportionate influence on the organization. For conflict, its manifestation usually leaves the organization with two opposing consequences. When functional conflict is predominant in an organization, it brings about positive contributions in the organization. According to Wobodo (2019) organizations directly and indirectly benefit from functional conflict as it brings out the best in teams and groups; thus enhancing their optimum performance. He further contends that through functional conflict, organizations build strong competitive advantage through innovation and creative idea sharing among teams and group members. While dysfunctional conflict on the other hand, plants discord and acts of sabotage among teams and group members, thereby making it a destructive and unwanted phenomenon that managers must have to deal with ruthlessly in order to succeed. Unlike conflict that provides both positive and negative impacts on the 
organization, the occurrence of crisis whether natural or man-made only leaves the organization in state of danger. It is completely associated with huge threat without any significant opportunity imbedded in it to explore. Crisis attacks the organization directly and determine whether it survives or dies prematurely.

Thirdly, in terms of management and control, both conflict and crisis are manageable phenomena but unequally controllable. In the management of conflict, the adoption of a given strategy is dependent on the gravity of the conflict as well as the disparity in the caliber of parties in conflict. In the area of control, all forms and levels of conflict can be adequately controlled, especially when appropriate policies and rules are put in place to regulate behavioral patterns and expectations of groups. Crisis on the other hand can be managed depending on the proactiveness and reactiveness of the manager in the face of the crisis and also the type of crisis being managed. Unlike conflict, not all crises are controllable, managers can easily manage and control man-made crisis but when it comes to natural crisis, managers only make efforts to mitigate its destructive implications while adapting to it. This view is in alignment with Harsch (2013) that organization can make a recovery strategy when the preventive implementation cannot survive the crisis, especially natural crisis. This is also because when such crisis occurs, it brings threats and urgency and leaves little time for organizations to respond (Subrt, 2014).

\section{Conclusion and Recommendations}

Consolidating on the literature explored thus far, we discovered that both conflict and crisis phenomena are indispensible part of human interaction and environmental character. The comparative analysis explored showed that both phenomena impact on the organization negatively but at varied degrees. Crises are mainly associated with disaster and hazard that ruthlessly negate the functionality of the organization if urgent response is not taken to mitigate it, while this goes; conflict in itself is not completely such a dangerous phenomenon in its entirety as mangers and scholars superficially perceive it to be. It is like a coin with two sides, the head and the tail; where the head represents success and the tail represents failure. The functional aspect impacts on the organization positively while the dysfunctional aspect leaves the organization with negative and destructive impact just like crisis. Therefore, we conclude that both conflict and crisis are inherent phenomena among people and their environments and of course cannot be eradicated but can only be managed through the adoption of approach context-fit strategies. In this regards, we recommend that: i) in the face of conflict and crisis, the choice of management approach should mainly be guided by its type, level and phase ii) since conflict and crisis are endemic factors, managers should regularly carry out both internal and external diagnosis as a means of identifying early warning signs of disruptive conflicts and natural crisis's incubation period and possible manifestation time so as to provide adequate proactive and reactive strategies to handle it ahead of time.

\section{REFERENCES}

Abd-Elaal, R. (2008). Methods of crises management to public schools principals in Gaza Governorates and their relationship to strategic planning. Master Thesis, Islamic University, Faculty of Education, Educational Administration Department, Palestine.

Akume, A. \& Abdullahi, Y. (2013). Challenges and prospects of effective industrial conflict resolution in Nigeria. Journal of Social Sciences, 36(2), 119-208.

Bailey, V. (2016). Proactive or reactive leadership, which is most effective in the workplace? Accessed 28/6/19 from https://blog.vistage.co.uk/proactive-or-reactive-leadership-which-is-most-effective-in-the-workplace.

Bello, M. (2011). Strategies for sustainable business environment in Nigeria. A Paper Presented at National Conference on Economic Transformation Agenda, held in Abuja, October, 2011.

Bouquet, C. \& Birkinshaw, J. (2008). Managing power in the Multinational Corporation: How low-power actors gain influence. Journal of Management, 34 (3), 477-508.

Calha, A. (2017). Interpersonal conflict management strategies in nursing teams. Research, Innovation and Development in Nursing Conference Proceedings International Congress.

Cropanzano, R., \& Mitchell, M. S. (2005). Social exchange theory: An interdisciplinary review. Journal of Management, 31(6), 874-900.

Deutsch, M. (1990). Sixty years of conflict. International Journal of Conflict Management, 1(3), 237-263.

El-Mahdi S. \& Hiba, H. (2002). Behavioral practices of school managers in dealing with crises inside the school. Journal of the Faculty of Education and Psychology 26(2), 221-143.

Gabriel, J.M.O. (2018). Business management: An indigenous standpoint. Nigeria: University of Port Harcourt Press.

Harsch, F.M. (2013). The power of dependence: NATO-UN Cooperation in crisis management. Berlin: Freie University Dissertation. [Published] Harsch, F.M., 2015. The Power of Dependence: NATO-UN Cooperation in Crisis Management. Oxford: Oxford University Press.

Hotepo, O.M., Asokere, A.S., Abdul-Azeez I.A. \& Asokere, S.A. (2010). Empirical study of the effect of conflict on organizational performance in Nigeria. Business and Economic Journal, 3(1), 1 - 9.

Hough, M., \& Spillan, J. (2005). Crisis planning: Increasing effectiveness, decreasing discomfort. Journal of 
Business and Economics Research 3, 19-24.

Iheriohanma, E.B. J (2007). The socio-economic issues challenging workers participation in management and productivity in Nigeria. IKOGHO: A Multi-Disciplinary Journal, 4(4), 1-11.

Karam M.G. (2018).The impact of strategic planning on crisis management styles in the 5-Star Hotels. Journal of Hotel Business Management, 7 (2), 171-183.

Kassim, M. \& Ibrahim, H. (2014). Conflict management styles and organizational commitment: A study among bank employees in Penang. International Journal of Business, Economics and Law, 4(1), 45-53.

Koontz, H. \& Weihrich, H. (1999). Management: A global perspective (11th ed.) Mexico: McGraw.

Hill, Mehrotra, S., Znati, I.T. \& Thompson, C.W. (2008). Crisis management: Guest editors' introduction. Published by the IEEE Computer Society.

Mullins, L. \& Christy, G. (2013). Management and organizational behavior (10th ed.). UK: Pearson.

Omoluabi, P. F. (2001). Principles and processes of conflictology. Ife Psychologia, 9(3), 1-13.

Oparanma, A.O. \& Wechie, I. (2014). Crisis management processes to ensure effective and continuous performance. Journal of Business and Management, 16(8), 01-04.

Robbins, S., Judge, T. \& Vohra, N. (2011).Organizational behavior (14th ed.), USA: Pearson as Prentice Hall.

Robbins, S.P. (2005) Organizational behavior (11th ed.) New Jersey: Pearson Education.

Ronez M. (2014).Crisis management in the workplace and the role of the HR team, on author's professional. Available at:htp://riskmanagementdemystiiedcom/2014/08/25/hr-a-key-role-to play-in-crisis-managementorganizational-sustainability-preparedness/. Accessed 21/3/2019.

Rotter, J. B. (1966). Generalized expectancies for internal versus external control of reinforcement. Psychological Monographs, 80 (1), 609-613.

Salami S. O. (2009). Conflict resolution strategies and organizational citizenship behavior: The moderating role of trait emotional intelligence. European Journal of Psychology, 5(7), 41 - 63.

Snell, B. (2002). Management: Competing in the new era. New York: McGraw-Hill.

Taher, M.A, Das, A.K. \& Rashed, M.S. (2008). Conflict management and its impact on organizational performance: A study on some industrial enterprises in Bangladesh. The Chittagong University Journal of Business Administration, 23(7), 9-31.

Thakore, D. (2013). Conflict and conflict management. Journal of Business and Management, 8 (6) 7-16.

Wobodo, C.C. \& Oparanma, A.O. (2019). Crisis management and corporate resilience of multinational oil and gas companies in Rivers State: A theoretical perspective. American Journal of Humanities and Social Sciences Research 3 (5), 7-14.

Wobodo, C.C. (2019). Conflict management strategies and industrial harmony: A theoretical review of Rivers State University, Port Harcourt. The Strategic Journal of Business \& Change Management, 6 (2), 981 - 994.

Wobodo, C.C., Asawo, S.P. \& Asawo, S.S. (2018). Knowledge sharing and employee resilience. Nigerian Business and Social Review, 9(2), 1-16. 